\title{
Biomechanical assessment of the paediatric foot: using the current evidence
}

\author{
Angela M Evans ${ }^{1,2^{*}}$, Keith Rome ${ }^{1}$ \\ From 3rd Congress of the International Foot and Ankle Biomechanics Community \\ Sydney, Australia. 11-13 April 2012
}

\section{Background}

The paediatric flat foot is a frequent presentation in clinical practice, a common concern to parents and continues to be debated. As an entity, it is confused by varied classifications, the notion of well-intended prevention and unsubstantiated, if common, treatment [1]. The paediatric flat foot proforma (p-FFP) is a standardized framework from which to evaluate the paediatric flat foot [2].

\section{Materials and methods}

An algorithm, extending the p-FFP, has been developed to direct assessment and management of the paediatric flatfoot. Based upon best available evidence, this model includes joint hypermobility, body weight and gender as relevant items to assess [3]. The normative data sets using the foot posture index are included and recent reliability studies [4] have identified the value of the ankle lunge test, Beighton scale and the lower limb assessment score in evaluation joint range, hypermobility and quality of life (Table 1).

\section{Results}

A recent critical literature review has identified that the resting calcaneal stance position (RCSP), navicular height and Foot Posture Index (FPI-6) are the only three reliable measures of static foot posture [5].

\section{Conclusions}

Further research is required to establish a universal method of assessment of paediatric foot posture. The relevance of static foot posture to pain and shod gait
Table 1 Inter-rater reliability: mean inter-rater ICC's (95\% $\left.\mathrm{Cl}^{\prime} \mathbf{s}\right)$ and SEM in children aged seven to 15 years $(\mathbf{n}=\mathbf{3 0})$

\begin{tabular}{llll}
\hline Variable & ICC $(95 \% \mathrm{Cl})$ & Mean (SD) & SEM \\
\hline Foot Posture Index & $0.79(0.38-0.94)$ & $4.3(2.7)$ & 1.3 \\
Lunge Test & $0.83(0.56-0.94)$ & $43.7(5.0)$ & $2.9 \mathrm{deg}$ \\
Beighton Scale & $0.73(0.42-0.88)$ & $2.4(1.2)$ & 1.2 \\
Lower Limb Assessment Score & $0.78(0.41-0.93)$ & $9.7(3.3)$ & 2.5 \\
\hline
\end{tabular}

function remains largely unsubstantiated in children, and warrants further investigation.

\section{Author details}

'Health \& Rehabilitation Research Institute, AUT University, Auckland, 92006, New Zealand. ${ }^{2}$ University of South Australia, Adelaide, 5000, Australia.

Published: 10 April 2012

\section{References}

1. Rome K, Ashford RL, Evans AM: Non-surgical interventions for paediatric pes planus (Review). Cochrane Database Syst Rev 2010, 7, DOI:10.1002 /14651858.CD006311.pub2.

2. Evans AM, Nicholson H, Zakaris $N$ : The paediatric flat foot proforma ( $\mathrm{p}$ FFP): improved and abridged following a reproducibility study. J Foot Ankle Res 2009, 2:25.

3. Evans AM, Rome K: A Cochrane review of the evidence for non-surgical interventions for flexible pediatric flat feet. Eur J Phys Rehabil Med 2011, 47:69-89.

4. Evans AM, Rome K, Peet L: The Foot posture index, Ankle lunge test, Beighton scale and the Lower Limb Assessment Score in healthy children: a reliability study. 2011, Under review.

5. Kneebone KA, Scutter SD, Evans AM: Clinical measures of paediatric foot posture: a critical review. 2011, Under review.

\section{doi:10.1186/1757-1146-5-S1-P7}

Cite this article as: Evans and Rome: Biomechanical assessment of the paediatric foot: using the current evidence. Journal of Foot and Ankle Research 2012 5(Suppl 1):P7.

\footnotetext{
* Correspondence: angelamevans@me.com

'Health \& Rehabilitation Research Institute, AUT University, Auckland, 92006, New Zealand

Full list of author information is available at the end of the article
}

(c) 2012 Evans and Rome; licensee BioMed Central Ltd. This is an Open Access article distributed under the terms of the Creative 